\title{
Duration of antidepressant use during pregnancy and risk of major congenital malformations
}

\author{
Élodie Ramos, Martin St-André, Évelyne Rey, Driss Oraichi and Anick Bérard
}

\section{Background}

Antidepressant use during the gestational period is a controversial topic.
Aims
To determine whether duration of antidepressant use during the first trimester increases the risk of major congenital malformations in offspring of women diagnosed with psychiatric disorders.

\begin{abstract}
Method
A case-control study was performed among women who had been pregnant between January 1998 and December 2002. Data were obtained from a Medication and Pregnancy Quebec, and a self-administered questionnaire. Women eligible for this study had to be 15-45 years old at the beginning of pregnancy, have at least one diagnosis of psychiatric disorder before pregnancy, have used antidepressants for $\geqslant 30$ days in the year prior to pregnancy and have a pregnancy ending with a delivery. Cases were defined as any major congenital malformation diagnosed in the offspring's first year of life. Odds ratios, adjusted for
\end{abstract} registry, built by linking three databases from the province of

relevant confounders, were estimated using logistic regression.

\section{Results}

Among the 2329 women meeting the inclusion criteria, 189 (8.1\%) infants were born with a major congenital malformation. Duration of antidepressant use during the first trimester of pregnancy was not associated with an increased risk of major congenital malformations: 1-30 days $v$. 0 day, adjusted $\mathrm{OR}=1.23$ (95\% $\mathrm{Cl}$ 0.77-1.98); 31-60 days $v$. 0 day, adjusted $\mathrm{OR}=1.03(95 \% \mathrm{Cl} 0.63-1.69) ; \geqslant 61$ days v. 0 day, adjusted $\mathrm{OR}=0.92(95 \% \mathrm{Cl} 0.50-1.69)$.

\section{Conclusions}

These data do not support an association between duration of antidepressant use during the first trimester of pregnancy and major congenital malformations in the offspring of women with psychiatric disorders. These findings should help clinicians decide whether to continue antidepressant therapy during pregnancy.

\section{Declaration of interest}

None.
Depression, anxiety disorders, anorexia nervosa and bulimia, which are indications for antidepressant pharmacotherapy, are common disorders in women of childbearing age, with a prevalence ranging from $3.7 \%$ to $14 \%{ }^{1,2}$ Given that $50 \%$ of pregnancies in North America are unplanned, ${ }^{3}$ the safety of antidepressants during the first trimester of pregnancy - a critical period for foetal development - has become a major public health concern. Indeed, several studies have shown that inadequate treatment of women with psychiatric disorders during the gestational period puts them at risk of developing poor health behaviours such as cigarette smoking, and alcohol and substance misuse. ${ }^{4}$ In addition, Cohen et al reported high rates of relapse of depression among pregnant women who discontinued antidepressant therapy around the time of conception compared with those who maintained antidepressant therapy during the same period. ${ }^{5}$ Recently, studies and warnings from Health Canada and the US Food and Drug Administration have left a lingering uncertainty regarding the adverse effects of antidepressants on the foetus. ${ }^{6,7}$ This uncertainty has been fuelled by reports suggesting an association between antidepressants and major congenital malformations, ${ }^{8-10}$ and those suggesting no association. ${ }^{11-14}$ Consequently, women with psychiatric disorders who are planning to conceive are faced with the difficulty of deciding whether to continue or discontinue their antidepressant therapy during pregnancy.

Thus far, studies that have investigated the association between antidepressant use during pregnancy and major congenital malformations have had several methodological problems limiting their interpretation. Indeed, most studies did not adequately control for psychiatric disorders, which have been shown to be independent predictors of negative pregnancy outcomes. ${ }^{15-18}$ Hence, it is important to separate the effects of antidepressant exposure and those of psychiatric disorders in relation to major congenital malformations. In addition, antidepressant use during pregnancy was often ill-defined (dichotomously) without taking into account the effect of the duration of the treatment on the occurrence of birth defects. Therefore, the objective of our study was to determine whether the duration of antidepressant use during the first trimester of pregnancy increases the risk of major congenital malformations in a large cohort of women who were diagnosed with a psychiatric disorder prior to pregnancy.

\section{Method}

\section{Data sources}

We used three administrative databases of the Province of Quebec, Canada: the Régie de l'Assurance Maladie du Québec (RAMQ), Maintenance et Exploitation des Données pour l'Étude de la Clientèle Hospitalière (MED-ECHO) and the Fichier des Événements Démographiques du Québec (ISQ; birth and death registries), managed by the Institut de la Statistique du Québec. Data extracted from these databases were supplemented with data obtained from a self-administered questionnaire.

The RAMQ database contains information on medical services (diagnoses and procedures) received by all Quebec residents. All diagnoses are classified according to the ICD-9. ${ }^{19}$ Although RAMQ covers all Quebec residents for the cost of physician visits, hospitalisations and procedures, it covers only a proportion of residents for the cost of medications. The RAMQ drug plan covers 
individuals aged 65 years and older, recipients of social assistance (welfare recipients), and workers and their families (adherents) who do not have access to a private drug insurance programme, accounting for approximately $43 \%$ of the overall Quebec population. ${ }^{20}$ It is also estimated that $30 \%$ of women aged $15-45$ years in Quebec are covered by the RAMQ drug plan for their medications (RAMQ data). The MED-ECHO database is a provincial database which records acute care hospitalisation data for all Quebec residents; it also records gestational age for deliveries (gestational age is validated data from the MED-ECHO archive), planned abortions and miscarriages. The ISQ provides demographic information on the mother, father and baby, as well as birth weight and gestational age for live births and stillbirths. The linkage between the three databases was done using patients' numéro d'assurance maladie, which is the unique identifier for all Quebec residents (RAMQ and MED-ECHO), and using mothers' and babies' dates of birth, first names and family names (RAMQ and ISQ). Each woman was linked to her child through the RAMQ databases to obtain information on medical services used, and medication dispensed before and during pregnancy. The mother-child pair was also linked with MED-ECHO and ISQ databases to obtain information on hospital admissions and socio-demographic variables.

The RAMQ, MED-ECHO and ISQ databases have often been used in the past for perinatal epidemiological research. ${ }^{8,21-24}$ Data recorded in the medication database of the RAMQ have been suitably evaluated and found to be comprehensive and valid. ${ }^{25}$ The same was found for medical diagnoses recorded in the MED-ECHO database. ${ }^{26}$

With regard to our study question, the administrative databases used here lacked data on important confounders such as pregnancy history, socio-demographic status (income, education, ethnicity) and lifestyles (tobacco, alcohol, illicit drugs). These data were obtained using a self-administered questionnaire developed for the purposes of this study. The questionnaire was mailed to all cohort members.

The study was approved by the Sainte-Justine Hospital ethics committee. All women who responded to the questionnaire gave their informed consent. The linkages between administrative databases and the self-administered questionnaire were approved by the Commission d'Accès à l'Information du Québec.

\section{Study population}

Using the RAMQ databases, a cohort of pregnant women was identified between 1 January 1998 and 31 December 2002. All women were aged between 15 years and 45 years on the first day of gestation (data available in MED-ECHO and ISQ databases). Pregnancies were identified using diagnostic and procedure codes related to the gestational period. All pregnant women in the cohort had to be insured for their medications by the RAMQ drug plan for at least 1 year before their first day of gestation and during their pregnancy. For this study, women also had to have received at least one diagnosis of a psychiatric disorder defined according to the ICD-9 classification (codes 290-319) before pregnancy; have used antidepressants for at least 30 days in the year prior to pregnancy; and have had a pregnancy ending with a delivery (live birth or stillbirth). Women with a particular diagnosis of psychotic/non-psychotic conditions or of mental retardation (ICD-9 codes 290-295, 297-299, 302, 303, 305-308, 312, 314-319) were excluded since they were unlikely to have been exposed to antidepressants. Women who had had an abortion or a miscarriage were also excluded, as well as those who had no recorded birth in the database. If a woman had more than one infant for a given pregnancy, each infant was considered independently in the analysis, and sensitivity analyses were then conducted to determine the potential impact of the correlation between pregnancies on the estimates. Finally, if a woman had more than one pregnancy between 1998 and 2002, the first pregnancy meeting the eligibility criteria was considered for analysis.

\section{Study design}

Within the cohort outlined above, a case-control study was performed to determine whether antidepressant duration during the first trimester of pregnancy increased the risk of major congenital malformations. Cases were identified according to the diagnostic codes described below. The index date for both cases and controls was the time of the delivery.

\section{Case definition}

Women were assigned to the 'case' group if their infants were diagnosed with at least one major congenital malformation identified at delivery or during the 12 months after delivery belonging to the following categories of congenital anomaly: ICD-9 code 740, anencephalus and similar anomalies; 741, spina bifida; 742, other congenital anomalies of nervous system; 743, congenital anomalies of eye; 744, congenital anomalies of ear, face and neck; 745, bulbus cordis anomalies and anomalies of cardiac septal closure; 746 , other congenital anomalies of heart; 747, other congenital anomalies of circulatory system; 748, congenital anomalies of respiratory system; 749, cleft palate and cleft lip; 750, other congenital anomalies of upper alimentary tract; 751 , other congenital anomalies of digestive system; 752, congenital anomalies of genital organs; 753, congenital anomalies of urinary system; 754, certain congenital musculoskeletal deformities; 755 , other congenital anomalies of limbs; 756, other congenital musculoskeletal anomalies; 757, congenital anomalies of the integument; 758, chromosomal anomalies; 759, other and unspecified congenital anomalies. We considered the year following delivery in order to identify as many birth defects as possible, given the fact that congenital malformation diagnoses could have been delayed. Only major congenital malformations were considered, and thus minor malformations were excluded (ICD-9 codes 743.6, 744.1, 744.2$744.4,744.8,744.9,747.0,747.5,750.0,752.4,752.5,754.6$, $755.0,755.1,757.2-757.6,757.8,757.9,758.4) .{ }^{27}$ We also assigned to the case group women whose infants were stillborn, in order not to underestimate the association between duration of antidepressant use and major congenital malformations.

The control group comprised women whose infants were not diagnosed with any congenital malformation.

\section{Assessment of exposure}

For each case and control we assessed exposure to antidepressants during the first trimester of pregnancy $(0-14$ weeks of gestational age). An algorithm was developed to calculate the exact number of days of antidepressant use for each woman by adding all antidepressant prescription durations over the length of the first trimester. Women were considered to be exposed to antidepressant use if they filled prescriptions for at least one antidepressant in the first trimester or if they filled prescriptions for at least an antidepressant before the first day of gestation but where the duration of the treatment lasted into the first trimester. This algorithm also took into account the time between renewals and overlap between antidepressant prescriptions. Hence, exposure to antidepressants during the first trimester was defined according to three definitions: 
(a) dichotomously (yes or no);

(b) duration of use, defined as the number of days exposed in the first trimester: 0 day, $1-30$ days, $31-60$ days and $\geqslant 61$ days;

(c) therapeutic class: selective serotonin reuptake inhibitors (SSRIs), tricyclic antidepressants, new antidepressants, and co-exposures (two more drug classes) in the first trimester.

Antidepressants considered were SSRIs (citalopram, fluoxetine, fluvoxamine, paroxetine and sertraline), tricyclic antidepressants (amitriptyline, clomipramine, desipramine, doxepin, imipramine, nortriptyline and trimipramine) and new antidepressants (bupropion, mirtazapine, moclobemide, nefazodone, trazodone and venlafaxine).

\section{Confounding variables}

Potential confounders included maternal age, socio-economic status based on receipt of social welfare, income $(>\$ 30000 v$. $\leqslant \$ 30000$, in Canadian dollars), area of residence (rural $v$. urban), ethnicity (Black, or Other $v$. White) and marital status (living alone $v$. not living alone) on the first day of gestation. Healthcare use variables (including the number of different prescribers, the number of different medications used other than antidepressants, visits to the emergency department or hospitalisations, number of visits to the physician, and maternal chronic diseases such as chronic and gestational diabetes (ICD-9 codes 250.0-250.9, 271.4, 790.2, 648.0 and 648.8, and use of oral hypoglycaemic drugs or insulin), chronic and gestational hypertension (ICD-9 codes 401.0-405.9, 362.1, 416.0, 437.2 and 796.2, and use of antihypertensive drugs) and asthma (ICD-9 code 493, and use of asthma drugs)) were measured the year before and during pregnancy, and were selected as markers of comorbidity. Pregnancy-related variables included whether there was a pregnancy in the year prior to the current pregnancy, the number of prenatal visits, the gender of the baby and the year of the beginning of the pregnancy. To take into account the severity of psychiatric disorders, the following markers were included: number of days on antidepressants in the year before pregnancy, number of psychiatric disorder diagnoses received before and during pregnancy, number of visits to the psychiatrist the year before and during pregnancy, use of anxiolytic/sedative drugs such as benzodiazepines and of anticonvulsants such as barbiturates during pregnancy, and antidepressant use during the second and third trimesters of pregnancy.

The following lifestyle variables were considered during pregnancy: tobacco use (quitted smoking, continued smoking $v$. non-smokers), alcohol use (yes $v$. no) and illicit drug use (yes v. no).

\section{Statistical analysis}

Descriptive statistics were used to summarise the characteristics of the study population. Using unconditional logistic regression models, we estimated crude and adjusted odds ratios along with 95\% confidence intervals for the association between antidepressant use during pregnancy and risk of major congenital malformations. Subgroup analyses were performed on data of women who responded to the questionnaire, to determine whether adjustment for confounders not available in administrative databases altered the results. All analyses were two-tailed and $P<0.05$ was considered significant. Software SAS version 8.2 for Windows was used to perform analyses.

\section{Results}

Among the 109344 women who were pregnant between 1 January 1998 and 31 December 2002, we identified 2329 women who met the eligibility criteria and thus constituted the study cohort. Of these 2329 women, $7(0.3 \%)$ had a stillbirth. Socio-demographic characteristics and healthcare use in this cohort are presented in Table 1. The cohort accrued a total of 3722 ICD-9 codes. The most frequent psychiatric disorders identified before pregnancy were anxiety $(n=979,26.3 \%)$, depressive disorders ( $n=929$, $25.0 \%)$ and dysthymic disorders $(n=353,9.5 \%)$. These psychiatric disorders were also the most frequently diagnosed during pregnancy: anxiety $(n=416,30.2 \%)$, depressive disorders $(n=253$, $18.4 \%)$ and dysthymic disorders $(n=152,11.0 \%)$. Paroxetine $(n=440,36.4 \%)$, sertraline $(n=178,14.7 \%)$ and venlafaxine $(n=155,12.8 \%)$ were the most frequently prescribed antidepressants during the first trimester. Paroxetine $(n=231$, $42.4 \%)$, sertraline $(n=80,14.7 \%)$ and fluoxetine $(n=51,9.4 \%)$ were the most frequently prescribed antidepressants during the second trimester. Finally, a similar pattern of prescriptions was observed during the third trimester: paroxetine $(n=219,44.3 \%)$, sertraline $(n=75,15.2 \%)$ and fluoxetine $(n=47,9.5 \%)$. Of all co-exposures during the first trimester (SSRIs plus new antidepressants; SSRIs plus tricyclics; tricyclics plus new antidepressants), the SSRI plus new antidepressant co-exposure was the most prevalent: $n=65$ (73.9\%). The mean duration of antidepressant use during the first trimester of pregnancy was 55 days (s.d.=29.2). Other medications used during the first trimester were most commonly anti-emetic $(n=619,12.1 \%)$, anti-infectious ( $n=487,9.5 \%)$, anxiolytic/sedative $(n=316,6.2 \%)$, anticonvulsive ( $n=279,5.5 \%)$, and sympathomimetic $(n=205,4.0 \%)$.

Within the study population, $189(8.1 \%, 95 \%$ CI $7.0-9.2)$ infants with at least one major congenital malformation were identified. A total of 265 major malformations were reported. The most frequent major congenital malformation was ostium secundum-type atrial septal defect: $n=32$ (12.1\%) (Table 2). This congenital malformation was not specific to any one class of antidepressant. Indeed, its presence was found in cases of women who used SSRIs or new antidepressants, women who had received two or more classes of drugs, and women who did not use an antidepressant at all during the first trimester of pregnancy (Table 2).

Antidepressant use during the first trimester of pregnancy defined in a dichotomous fashion was not statistically associated with having an infant with a major congenital malformation (adjusted OR=1.10, 95\% CI 0.75-1.62; Table 3). Duration of antidepressant exposure during the first trimester was also not statistically associated with major congenital malformations (Table 4). No association was found between the class of antidepressant used during the first trimester of pregnancy and the occurrence of major congenital malformations (Table 5).

\section{Subgroup analysis}

Of the 2329 pregnant women who met eligibility criteria, 806 (34.6\%) responded to the questionnaire. Responders were similar to non-responders (Table1). Of those who responded, 59 (7.3\%) had an infant with at least one major congenital malformation. Adjustment for variables such as tobacco, alcohol or illicit drug use, income and ethnicity did not alter the results: 1-30 days $v$. 0 day, adjusted $\mathrm{OR}=1.19$ (95\% CI $0.51-2.79) ; 31-60$ days $v .0$ day, adjusted $\mathrm{OR}=0.46(95 \%$ CI $0.15-1.40) ; \geqslant 61$ days $v .0$ day, adjusted $\mathrm{OR}=0.31(95 \% \mathrm{CI} 0.10-1.23)$. 


\begin{tabular}{|c|c|c|c|c|}
\hline \multirow[b]{2}{*}{ Variables } & \multicolumn{2}{|c|}{ Data from the administrative databases $(n=2329)$} & \multicolumn{2}{|c|}{ Data from the questionnaire $(n=806)$} \\
\hline & Case group ( $n=189$ ) & Control group ( $n=2140$ ) & Case group ( $n=59$ ) & Control group ( $n=747)$ \\
\hline \multicolumn{5}{|l|}{$\begin{array}{l}\text { Measured on the first day of gestation } \\
\text { Socio-demographic }\end{array}$} \\
\hline Maternal age, years: mean (s.d.) & $28.3(5.7)$ & $28.3(6.0)$ & $26.5(5.45)$ & $28.2(6.0)$ \\
\hline Urban dweller, $n(\%)$ & $154(81.5)$ & $1641(76.7)$ & $44(74.6)$ & $546(73.1)$ \\
\hline Income > CAN\$30 000, n (\%) & NA & NA & $23(40.0)$ & $221(29.6)$ \\
\hline Welfare recipient, $n(\%)$ & $89(47.1)$ & $988(46.2)$ & $35(59.3)$ & $472(63.2)$ \\
\hline Living alone, $n(\%)$ & $67(35.5)$ & $628(29.4)$ & $21(35.6)$ & $182(24.4)$ \\
\hline \multicolumn{5}{|l|}{ Ethnicity, $n(\%)$} \\
\hline White & NA & NA & $46(78.0)$ & $658(88.1)$ \\
\hline Black & NA & NA & $5(8.5)$ & $10(1.3)$ \\
\hline Other & NA & NA & $8(13.6)$ & $79(10.6)$ \\
\hline \multicolumn{5}{|l|}{$\begin{array}{l}\text { Measured in year before pregnancy } \\
\text { Psychiatric disorder-related }\end{array}$} \\
\hline \multicolumn{5}{|l|}{ Number of depression diagnoses, $n$ (\%) } \\
\hline $1-2$ & $96(50.8)$ & $1133(52.9)$ & $28(47.5)$ & $385(51.5)$ \\
\hline $3-5$ & $48(25.4)$ & $565(26.4)$ & $18(30.5)$ & $198(26.5)$ \\
\hline$\geqslant 6$ & $45(23.8)$ & $442(20.7)$ & $13(22.0)$ & $164(22.0)$ \\
\hline At least one visit to the psychiatrist, $n$ (\%) & $60(31.8)$ & $582(27.2)$ & $18(30.5)$ & $190(25.4)$ \\
\hline \multicolumn{5}{|l|}{ Days of exposure to antidepressants, $n$ (\%) } \\
\hline 30-120 days & $101(53.4)$ & $1118(52.2)$ & $36(61.0)$ & $354(47.4)$ \\
\hline $121-180$ days & $23(12.2)$ & $310(14.5)$ & $3(5.1)$ & $112(15.0)$ \\
\hline$\geqslant 181$ days & $65(34.4)$ & 712 (33.3) & $20(33.9)$ & $281(37.6)$ \\
\hline \\
\hline \multicolumn{5}{|l|}{ Psychiatric disorder-related } \\
\hline At least one depression diagnosis, $n(\%)$ & $71(37.6)$ & 822 (38.4) & $21(35.6)$ & $286(38.3)$ \\
\hline At least one visit to the psychiatrist, $n(\%)$ & $30(15.9)$ & $315(14.7)$ & $9(15.3)$ & $105(14.1)$ \\
\hline At least one anxiolytic/sedative prescription, $n(\%)$ & $43(22.8)$ & $396(18.5)$ & $10(17.0)$ & $127(17)$ \\
\hline At least one anticonvulsive prescription, $n(\%)$ & $32(16.9)$ & $268(12.5)$ & $7(11.9)$ & $83(11.1)$ \\
\hline \multicolumn{5}{|l|}{ Lifestyle-related, $n(\%)$} \\
\hline \multicolumn{5}{|l|}{ Tobacco } \\
\hline Non-smoker & & & $30(50.9)$ & $432(57.8)$ \\
\hline Quit smoking & NA & NA & $7(11.9)$ & $61(8.2)$ \\
\hline Continued smoking & NA & NA & $22(37.3)$ & $254(34.0)$ \\
\hline Alcohol & NA & NA & $7(11.9)$ & $152(20.4)$ \\
\hline Illicit drugs & NA & NA & $3(5.1)$ & $52(7)$ \\
\hline \multicolumn{5}{|l|}{ Chronic diseases } \\
\hline Diabetes mellitus, $n$ (\%) & $18(9.5)$ & $187(8.7)$ & $5(8.5)$ & $61(8.2)$ \\
\hline Hypertension, $n(\%)$ & $22(11.6)$ & $196(9.2)$ & $8(13.6)$ & 80 (10.7) \\
\hline Asthma, $n$ (\%) & $51(27.0)$ & 455 (21.3) & $16(27.1)$ & $164(22.0)$ \\
\hline
\end{tabular}

\section{Sensitivity analyses}

Given that $1.2 \%(n=28)$ women had multiple births and thus contributed more than once in the analyses, the analyses were repeated for singleton births alone to determine whether the potential correlation between pregnancies affected the estimates. The results were similar to those presented in Tables 3-5. Sensitivity analyses were also conducted by excluding women who had a stillbirth. The results remained unchanged (data not shown).

\section{Discussion}

To our knowledge, this study is the first to investigate the impact of duration of antidepressant exposure during the first trimester of pregnancy on the occurrence of major congenital malformations. There was no difference between women who used antidepressants during the first trimester of pregnancy and those who used no antidepressants throughout pregnancy in terms of rates of major congenital malformations. Unlike previous studies, which considered antidepressant use in a dichotomous fashion, we considered also the number of days of antidepressant use during the first trimester. No statistically significant association was found between antidepressant duration during the first trimester of pregnancy and the risk of major congenital malformations in infants. In addition, the class of antidepressant used was not significantly associated with the occurrence of major birth defects.

Our study was designed to circumvent important methodological limitations present in previous studies. First, several studies selected comparison groups of women who did not have a psychiatric disorder. ${ }^{28}$ This may be problematic, since psychiatric disorders have been associated with negative pregnancy outcomes. ${ }^{15-18}$ To avoid this, we selected a large cohort of pregnant women diagnosed with psychiatric disorders before pregnancy, which enabled us to separate the effects of antidepressants from those of the psychiatric disorders. On the other hand, we cannot rule out the possibility that certain women decided to discontinue their treatment during pregnancy because their illness was not as severe as that of others, thus suggesting an indication bias. However, studies report that most women who decide to interrupt their antidepressant treatment during pregnancy do so because of an exaggerated perception of teratogenic risk and not because of severity of symptoms. ${ }^{29}$ Indeed, women who responded to the questionnaire and discontinued their antidepressant use were specifically asked the reasons for their discontinuation. The majority responded that they had 
Table 2 Major congenital malformations most frequently diagnosed, categorised by class of antidepressant used

Case group $(n=265)$

SSRIS, $n$

Other and unspecified anomalies of musculoskeletal system (ICD-9 code: 756.9)

Ostium secundum-type atrial septal defect (ICD-9: 745.5)

Certain congenital musculoskeletal deformities of skull, face and jaw (ICD-9: 754.0)

Tricyclic antidepressants, $n$

Unspecified anomaly of eye (ICD-9: 743.9)

Ventricular septal defect (ICD-9: 745.4)

Anomalies of pulmonary valve (ICD-9: 746.0)

New antidepressants, $n$

Ostium secundum-type atrial septal defect (ICD-9: 745.5)

Other and unspecified anomalies of musculoskeletal system (ICD-9: 756.9)

Unspecified anomaly of eye (ICD-9: 743.9)

No antidepressant,

Ostium secundum-type atrial septal defect (ICD-9: 745.5)

Other and unspecified anomalies of musculoskeletal system (ICD-9: 756.9)

Unspecified anomaly of eye (ICD-9: 743.9)

13

12

2

1

5

3

14

14

co-exposure, ${ }^{\mathrm{a}} \mathrm{n}$

Ostium secundum-type atrial septal defect (ICD-9: 745.5)

Certain congenital musculoskeletal deformities of skull, face and jaw (ICD-9: 754.0)

Unspecified anomaly of eye (ICD-9: 743.9)

SSRI, selective serotonin reuptake inhibitor.

a. Women who received two or more classes of antidepressant.

\section{Table 3 Risk of major congenital malformations associated with antidepressant use during pregnancy}

\begin{tabular}{|c|c|c|c|c|}
\hline & $\begin{array}{l}\text { Case group } \\
\qquad(n=189)\end{array}$ & $\begin{array}{l}\text { Control group } \\
\qquad(n=2140)\end{array}$ & $\begin{array}{l}\text { Unadjusted OR } \\
\quad(95 \% \mathrm{Cl})\end{array}$ & $\begin{array}{l}\text { Adjusted OR } \\
\qquad(95 \% \mathrm{Cl})^{\mathrm{a}}\end{array}$ \\
\hline Antidepressant exposure during first trimester (0-14 weeks), $n(\%)$ & $95(50.3)$ & $1006(47.0)$ & $1.10(0.75-1.62)$ & $1.10(0.75-1.62)$ \\
\hline Antidepressant exposure during second trimester (15-26 weeks), n (\%) & $45(23.8)$ & $465(21.7)$ & $1.13(0.59-1.60)$ & $1.13(0.59-2.17)$ \\
\hline Antidepressant exposure during third trimester (> 27 weeks), $n$ (\%) & $40(21.2)$ & $436(20.4)$ & $1.05(0.73-1.51)$ & $0.86(0.45-1.65)$ \\
\hline
\end{tabular}

a. Adjusted for maternal age, being on welfare, urban dweller, living alone, measures related to psychiatric disorders and measures of comorbidities not related to psychiatric disorders before and during pregnancy, hypertension and diabetes diagnoses before and during pregnancy, gender of baby, prenatal visits and year of pregnancy.

\begin{tabular}{|c|c|c|c|c|}
\hline & $\begin{array}{l}\text { Case group } \\
\qquad(n=189)\end{array}$ & $\begin{array}{l}\text { Control group } \\
\qquad(n=2140)\end{array}$ & $\begin{array}{l}\text { Unadjusted OR } \\
\quad(95 \% \mathrm{Cl})\end{array}$ & $\begin{array}{l}\text { Adjusted OR } \\
\qquad(95 \% \mathrm{CI})^{\mathrm{a}}\end{array}$ \\
\hline \multicolumn{5}{|l|}{ Antidepressant use during first trimester, $n(\%)$} \\
\hline 0 day & $94(49.7)$ & $1134(53.0)$ & 1.00 & 1.00 \\
\hline $1-30$ days & $28(14.8)$ & $273(12.8)$ & $1.24(0.80-1.93)$ & $1.23(0.77-1.98)$ \\
\hline $31-60$ days & $28(14.8)$ & $309(14.4)$ & $1.09(0.70-1.70)$ & $1.03(0.63-1.69)$ \\
\hline$\geqslant 61$ days & $39(20.6)$ & $424(19.8)$ & $1.11(0.75-1.64)$ & $0.92(0.50-1.69)$ \\
\hline Antidepressant use during second trimester, $n(\%)$ & $45(23.8)$ & $465(21.7)$ & $1.13(0.79-1.60)$ & $1.24(0.62-2.48)$ \\
\hline Antidepressant use during the third trimester, $n(\%)$ & $40(21.2)$ & $436(20.4)$ & $1.05(0.73-1.51)$ & $0.89(0.46-1.71)$ \\
\hline
\end{tabular}

discontinued because of possible teratogenic risks. Second, we were able to control for a variety of socio-demographic, pharmaceutical and healthcare-related variables that are available in administrative databases. These variables were potential risk factors for major congenital malformations before and during pregnancy. The use of the questionnaire also allowed us to perform subgroup analyses where we controlled for important lifestyle variables during pregnancy, including tobacco, alcohol and illicit drug use, none of which confounded the association of interest. Third, unlike previous studies that used only a dichotomous definition to describe antidepressant use during the first trimester of pregnancy, we employed three different definitions. The first was a dichotomous definition similar to that used in the earlier studies; this allowed us to compare our results with previously published reports. The second definition was the number of days of antidepressant use during the first trimester of pregnancy: this enabled us to investigate more precisely the impact of the duration of the therapy. The point estimate for exposure to antidepressant medication during the first trimester decreased as a function of antidepressant duration. An opposite trend would have been expected if duration of antidepressant use increased the risks of congenital anomalies. In fact, this may suggest that 


\begin{tabular}{|c|c|c|c|c|}
\hline & $\begin{array}{l}\text { Case group } \\
\qquad(n=189)\end{array}$ & $\begin{array}{l}\text { Control group } \\
\qquad(n=2140)\end{array}$ & $\begin{array}{c}\text { Crude OR } \\
(95 \% \mathrm{Cl})\end{array}$ & $\begin{array}{l}\text { Adjusted OR } \\
(95 \% \mathrm{Cl})^{\mathrm{a}}\end{array}$ \\
\hline \multicolumn{5}{|l|}{ Antidepressant use during the first trimester, $n(\%)$} \\
\hline None & $94(49.7)$ & $1134(53.0)$ & 1.00 & 1.00 \\
\hline Paroxetine $^{b}$ & $37(19.6)$ & $375(17.5)$ & $0.84(0.56-1.25)$ & $1.27(0.78-2.06)$ \\
\hline Other SSRI & $30(15.9)$ & $303(14.2)$ & $0.84(0.55-1.29)$ & $1.19(0.71-1.97)$ \\
\hline Tricyclic antidepressant & $5(2.7)$ & $78(3.6)$ & $1.29(0.51-3.27)$ & $0.78(0.30-2.02)$ \\
\hline New antidepressant & $15(7.9)$ & $167(7.8)$ & $0.93(0.52-1.63)$ & $0.94(0.51-1.75)$ \\
\hline Co-exposure & $8(4.2)$ & $83(3.9)$ & $0.86(0.40-1.83)$ & $1.03(0.44-2.41)$ \\
\hline Antidepressant use during the second trimester, $n(\%)$ & $45(23.8)$ & $465(21.7)$ & $1.13(0.79-1.60)$ & $1.07(0.54-2.11)$ \\
\hline Antidepressant use during the third trimester, $n$ (\%) & $40(21.2)$ & $436(20.4)$ & $1.05(0.73-1.51)$ & $0.74(0.37-1.49)$ \\
\hline
\end{tabular}

adequate control of psychiatric disorders with antidepressants during pregnancy might be associated with better pregnancy outcomes. Finally, because recent studies have investigated the association between SSRI use and congenital malformations, ${ }^{30,31}$ we conducted analyses to determine which antidepressant therapeutic class was associated with congenital malformations. We found no association between any therapeutic class and congenital malformations, although a tendency was observed for SSRIs. However, interestingly, none of the newborns had persistent pulmonary hypertension or patent ductus arteriosus, both of which were recently associated with SSRI exposure after the 20th week of gestational age. ${ }^{9}$

Administrative databases have the great potential of providing accurate information on medications dispensed throughout pregnancy. They give full details on the names, dosages, quantities and treatment duration of medications dispensed, thus offering information that is almost impossible to obtain by interviewing patients who have to recall their use of medications over an extended period. ${ }^{32-35}$ Field studies usually rely on self-reported medication histories and are prone to recall bias. On the other hand, the prevalence of antidepressant use was calculated on the basis of the drugs dispensed to study participants and does not necessarily reflect actual intake. However, we can safely assume that women continuously refilling their prescriptions (longer duration of treatment) actually take their medications. Furthermore, De Jong et al reported that $94 \%$ of all drugs dispensed to pregnant women are actually taken. ${ }^{36}$

The results of our study suggest that, as a whole, there is no association between duration of antidepressant use in the first trimester of pregnancy and the occurrence of major congenital malformations. Nevertheless, it may be possible that a specific antidepressant might cause a specific major congenital malformation. Ideally, it would have been preferable to determine the effect of each antidepressant type on specific major congenital malformations. However, this was not possible here since stratifying on antidepressant type would have further restricted our sample size. For this reason we limited our analyses according to antidepressant class. This limitation could explain the difference in the results observed with other studies. The reason for this is that each antidepressant has a different mechanism of action, even within the same therapeutic class, and thus each may be a teratogen at a different level. ${ }^{37}$ Investigating this would have required very large sample sizes for each antidepressant type, rendering such analyses infeasible in the present context.

Finally, the baseline prevalence of major congenital malformations in the general population is estimated at $1.5-3 \% .^{38}$ We found in our cohort a prevalence of major birth defects of $8.1 \%$. This could partly be explained by the fact that being an adherent of the RAMQ drug plan or a welfare recipient, and thus of lower socio-economic level, increased the likelihood of having a psychiatric illness $^{39}$ and consequently of giving birth to an unhealthy infant. However, it is important to point out that despite the fact that our cohort was composed of women who were welfare recipients and adherents of the RAMQ drug plan, our results are probably generalisable to women from other socio-economic backgrounds, since the association of antidepressant medication with major congenital malformations is likely to have more of a biological than a socio-economic basis.

\section{Future research}

We found no association between duration of antidepressant use during the first trimester and major congenital malformations. The results are concordant with most studies published thus far on this topic. Future studies should investigate the effect of individual antidepressants on specific major congenital malformations, taking into account the duration of exposure to antidepressants.

\section{Élodie Ramos, MSC, Faculty of Pharmacy, University of Montreal, and Research Center, Centre Hospitalier Universitaire (CHU) Sainte-Justine, Montreal; \\ Martin St-André, MD, Faculty of Medicine, University of Montreal, and Department of Psychiatry, CHU Sainte-Justine, Montreal; Évelyne Rey, MD, Research Center, $\mathrm{CHU}$ Sainte-Justine, Montreal, Faculty of Medicine, University of Montreal, and Canada Department of Obstetrics and Gynecology, CHU Sainte-Justine, Montreal; Driss Oraichi, PhD, Research Center, CHU Sainte-Justine, Montreal; Anick Bérard, PhD, Faculty of Pharmacy, University of Montreal, and Research Center, CHU Sainte- Justine, Montreal, Quebec, Canada}

Correspondence: Dr Anick Bérard, CHU Sainte-Justine, Research Center, 3175 chemin de la Côte-Ste-Catherine, Montreal, Quebec H3T 1C5, Canada. Email: anick.berard@umontreal.ca

First received 3 Jul 2007, final revision 27 Oct 2007, accepted 15 Jan 2008

\section{Acknowledgements}

This study was supported by the Fonds de la Recherche en Santé du Québec (FRSQ), grant number 6263, the Réseau Québécois de Recherche sur I'Usage des Médicaments and the FRSQ Network for the Wellbeing of Children. E.R. is the recipient of a PhD bursary from the CHU Sainte-Justine. A.B. is the recipient of a career award from the Canadian Institutes of Health Research/Health Research Foundation, and is the Endowment Research Chair of the Famille Louis-Boivin on Medications, Pregnancy and Lactation at the Faculty of Pharmacy of the University of Montreal. This study was presented in part at the Conference of the Réseau Québécois de Recherche sur I'Usage des Médicaments in Quebec City, Quebec, Canada, 5-6 June 2006, and in part at the Fourth Canadian Therapeutics Congress in Halifax, Nova Scotia, Canada, 27-30 May 2006 


\section{References}

1 Gentile S. The safety of newer antidepressants in pregnancy and breastfeeding. Drug Saf 2005; 28: 137-52.

2 Deering S. Eating disorders: recognition, evaluation, and implications for obstetrician/gynecologists (1). Prim Care Update Ob Gyns 2001; 8: 31-5.

3 Lancet. Better news on population. Lancet 1992; 339: 1600.

4 Zuckerman B, Amaro H, Bauchner H, Cabral H. Depressive symptoms during pregnancy: relationship to poor health behaviors. Am J Obstet Gynecol 1989; 160: $1107-11$

5 Cohen LS, Altshuler LL, Harlow BL, Nonacs R, Newport DJ, Viguera AC, Suri R Burt VK, Hendrick V, Reminick AM, Loughead A, Vitonis AF, Stowe ZN. Relapse of major depression during pregnancy in women who maintain or discontinue antidepressant treatment. JAMA 2006; 295: 499-507.

6 Public Health Agency of Canada. Canada Prenatal Nutrition Program (CPNP). PHAC, 2002 (http://www.phac-aspc.gc.ca/dca-dea/programs-mes/ cpnp_participants_e.html).

7 US Food and Drug Administration Center for Drug Evaluation and Research FDA Public Health Advisory Paroxetine 2005. FDA, 2005 (http://www.fda.gov/ cder/drug/advisory/paroxetine200512.htm).

8 Berard A, Ramos E, Rey E, Blais L, St-Andre M, Oraichi D. First trimester exposure to paroxetine and risk of cardiac malformations in infants: the importance of dosage. Birth Defects Res B Dev Reprod Toxicol 2007; 80 : 18-27.

9 Chambers CD, Hernandez-Diaz S, Van Marter U, Werler MM, Louik C, Jones $\mathrm{KL}$, Mitchell AA. Selective serotonin-reuptake inhibitors and risk of persistent pulmonary hypertension of the newborn. N Engl J Med 2006; 354: 579-87.

10 Kallen B, Otterblad Olausson P. Antidepressant drugs during pregnancy and infant congenital heart defect. Reprod Toxicol 2006; 21: 221-2.

11 Kulin NA, Pastuszak A, Sage SR, Schick-Boschetto B, Spivey G, Feldkamp M Ormond K, Matsui D, Stein-Schechman AK, Cook L, Brochu J, Rieder M, Koren G. Pregnancy outcome following maternal use of the new selective serotonin reuptake inhibitors: a prospective controlled multicenter study. JAMA 1998; 279: 609-10.

12 Pastuszak A, Schick-Boschetto B, Zuber C, Feldkamp M, Pinelli M, Sihn S, Donnenfeld A, McCormack M, Leen-Mitchell M, Woodland C, Gardner A, Horn M, Koren G. Pregnancy outcome following first-trimester exposure to fluoxetine (Prozac). JAMA 1993; 269: 2246-8.

13 Goldstein DJ, Corbin LA, Sundell KL. Effects of first-trimester fluoxetine exposure on the newborn. Obstet Gynecol 1997; 89: 713-8.

14 Einarson TR, Einarson A. Newer antidepressants in pregnancy and rates of major malformations: a meta-analysis of prospective comparative studies. Pharmacoepidemiol Drug Saf 2005; 14: 823-7.

15 Kinney DK, Yurgelun-Todd DA, Levy DL, Medoff D, Lajonchere CM, RadfordParegol M. Obstetrical complications in patients with bipolar disorder and their siblings. Psychiatry Res 1993; 48: 47-56.

16 Steer RA, Scholl TO, Hediger ML, Fischer RL. Self-reported depression and negative pregnancy outcomes. J Clin Epidemiol 1992; 45: 1093-9.

17 Orr ST, Miller CA. Maternal depressive symptoms and the risk of poor pregnancy outcome. Review of the literature and preliminary findings. Epidemiol Rev 1995; 17: 165-71.

18 Franko DL, Blais MA, Becker AE, Delinsky SS, Greenwood DN, Flores AT, Ekeblad ER, Eddy KT, Herzog DB. Pregnancy complications and neonatal outcomes in women with eating disorders. Am J Psychiatry 2001; 158 : 1461-6.

19 World Health Organization. International Statistical Classification of Diseases and Related Health Problems (ICD-9). WHO, 1978.
20 Régie de I'Assurance Maladie du Québec. Annual Statistics. Government of Quebec, 1997.

21 Ramos E, Oraichi D, Rey E, Blais L, Berard A. Prevalence and predictors of antidepressant use in a cohort of pregnant women. BJOG 2007; 114 1055-64.

22 Ofori B, Rey E, Berard A. Risk of congenital anomalies in pregnant users of statin drugs. Br J Clin Pharmacol 2007; 64: 496-509.

23 Martel MJ, Rey E, Beauchesne MF, Perreault S, Lefebvre G, Forget A, Blais L. Use of inhaled corticosteroids during pregnancy and risk of pregnancy induced hypertension: nested case-control study. BMJ 2005; 330: 230

24 Blais L, Beauchesne MF, Rey E, Malo JL, Forget A. Use of inhaled corticosteroids during the first trimester of pregnancy and the risk of congenital malformations among women with asthma. Thorax 2007; 62 320-8.

25 Tamblyn $\mathrm{R}$, Lavoie $\mathrm{G}$, Petrella $\mathrm{L}$, Monette J. The use of prescription claims databases in pharmacoepidemiological research: the accuracy and comprehensiveness of the prescription claims database in Quebec. J Clin Epidemiol 1995; 48: 999-1009.

26 Levy AR, Mayo NE, Grimard G. Rates of transcervical and pertrochanteric hip fractures in the province of Quebec, Canada, 1981-1992. Am J Epidemiol 1995; 142: 428-36

27 New York State Department of Health. Congenital Malformations Registry 1996 Report. Department of Health, 1996 (http://www.health.state.ny.us/ nysdoh/cmr/1996/append2.htm).

28 Chambers CD, Johnson KA, Dick LM, Felix RJ, Jones KL. Birth outcomes in pregnant women taking fluoxetine. N Engl J Med 1996; 335: 1010-5.

29 Bonari L, Koren G, Einarson TR, Jasper JD, Taddio A, Einarson A. Use of antidepressants by pregnant women: evaluation of perception of risk, efficacy of evidence based counseling and determinants of decision making. Arch Womens Ment Health 2005; 8: 214-20.

30 Louik C, Lin AE, Werler MM, Hernandez-Diaz S, Mitchell AA. First-trimester use of selective serotonin-reuptake inhibitors and the risk of birth defects. N Engl J Med 2007; 356: 2675-83.

31 Alwan S, Reefhuis J, Rasmussen SA, Olney RS, Friedman JM. Use of selective serotonin-reuptake inhibitors in pregnancy and the risk of birth defects. N Engl J Med 2007; 356: 2684-92.

32 Paganini-Hill A, Ross RK. Reliability of recall of drug usage and other healthrelated information. Am J Epidemiol 1982; 116: 114-22.

33 Tilley BC, Barnes AB, Bergstralh E, Labarthe D, Noller KL, Colton T, Adam E. A comparison of pregnancy history recall and medical records. Implications for retrospective studies. Am J Epidemiol 1985; 121: 269-81.

34 Van den Brandt PA, Petri H, Dorant E, Goldbohm RA, Van de Crommert S. Comparison of questionnaire information and pharmacy data on drug use. Pharm Weekbl Sci 1991; 13: 91-6.

35 West SL, Savitz DA, Koch G, Strom BL, Guess HA, Hartzema A. Recall accuracy for prescription medications: self-report compared with database information. Am J Epidemiol 1995; 142: 1103-12.

36 De Jong van den Berg LT, Feenstra N, Sorensen HT, Cornel MC. Improvement of drug exposure data in a registration of congenital anomalies. Pilot-study: pharmacist and mother as sources for drug exposure data during pregnancy. EuroMAP Group. European Medicine and Pregnancy Group. Teratology 1999: 60: 33-6.

37 Banhidy F, Lowry RB, Czeizel AE. Risk and benefit of drug use during pregnancy. Int J Med Sci 2005; 2: 100-6.

38 International Clearinghouse for Birth Defects Monitoring Systems. Annual Report. ICBDMS, 2003.

39 Murphy JM, Olivier DC, Monson RR, Sobol AM, Federman EB, Leighton AH. Depression and anxiety in relation to social status. A prospective epidemiologic study. Arch Gen Psychiatry 1991; 48: 223-9. 